\title{
Cytoplasmic SET induces tau hyperphosphorylation through a decrease of methylated phosphatase $2 \mathrm{~A}$
}

\author{
Stéphanie Chasseigneaux ${ }^{1,2,3,4 \dagger}$, Christine Clamagirand ${ }^{1 \dagger}$, Léa Huguet ${ }^{1}$, Lucie Gorisse-Hussonnois ${ }^{1}$, \\ Christiane Rose ${ }^{1}$ and Bernadette Allinquant ${ }^{1^{*}}$
}

\begin{abstract}
Background: The neuronal cytoplasmic localization of SET, an inhibitor of the phosphatase 2A (PP2A), results in tau hyperphosphorylation in the brains of Alzheimer patients through mechanisms that are still not well defined.

Results: We used primary neurons and mouse brain slices to show that SET is translocated to the cytoplasm in a manner independent of both its cleavage and over-expression. The localization of SET in the cytoplasm, either by the translocation of endogenous SET or by internalization of the recombinant full-length SET protein, induced tau hyperphosphorylation. Cytoplasmic recombinant full-length SET in mouse brain slices induced a decrease of PP2A activity through a decrease of methylated PP2A levels. The levels of methylated PP2A were negatively correlated with tau hyperphosphorylation at Ser-202 but not with the abnormal phosphorylation of tau at Ser-422.

Conclusions: The presence of full-length SET in the neuronal cytoplasm is sufficient to impair PP2A methylation and activity, leading to tau hyperphosphorylation. In addition, our data suggest that tau hyperphosphorylation is regulated by different mechanisms at distinct sites. The translocation of SET to the neuronal cytoplasm, the low activity of PP2A, and tau hyperphosphorylation are associated in the brains of Alzheimer patients. Our data show a link between the translocation of SET in the cytoplasm and the decrease of methylated PP2A levels leading to a decrease of PP2A activity and tau hyperphosphorylation. This chain of events may contribute to the pathogenesis of Alzheimer disease.
\end{abstract}

Keywords: Cytoplasmic SET, Protein Phosphatase 2A, Methyl Phosphatase 2A, Tau hyperphosphorylation, Alzheimer disease

\section{Background}

Hyperphosphorylation of tau, which leads to the formation of neurofibrillary tangles, is one of the two hallmarks of Alzheimer disease (AD) [1-3]. Tau phosphorylation is mainly regulated by the balance of kinases/phosphatases. Several kinases are involved in tau phosphorylation including the glycogen synthase kinase $3 \beta$ (GSK-3 $\beta$ ), MAP kinase (MEK1/2), neuronal cdc2-like kinase (NCLK) and cyclin dependent kinase 5 (cdk5) [1-3]. In contrast, few phosphatases dephosphorylate tau. Phosphatase 2A (PP2A), a serine/threonine phosphatase, is the most effective.

\footnotetext{
* Correspondence: bernadette.allinquant@inserm.fr

${ }^{\dagger}$ Equal contributors

'INSERM UMR 894, Université Paris Descartes, Sorbonne Paris Cité, Faculté de Médecine, Paris, France

Full list of author information is available at the end of the article
}

PP2A is a trimeric protein with a heterodimeric core enzyme consisting of a catalytic $C$ subunit (PP2Ac), and a scaffolding A subunit. This core enzyme associates with a variable regulatory subunit to form a heterotrimeric holoenzyme [4-6]. PP2A shows efficient enzymatic activity when it is methylated at Leu-309 [7-10] and unphosphorylated at Tyr-307 [11]. In the brain of AD patients, the activity of PP2A is compromised [12-14]. The decrease of PP2A methylation observed in brains of AD patients [15] may explain the decrease of PP2A activity and contribute to tau hyperphosphorylation $[16,17]$.

The activity of PP2A can be inhibited by two proteins: I1PP2A and I2PP2A, which is also called SET, TAF1 $\beta$, or PHAPII [18]. SET is a multifunctional protein: it inhibits the acetylation of histones [19], blocks DNase activity [20], acts as a transcription factor [21], and promotes tau phosphorylation by activating cdk5 [22], and inhibiting PP2A [23]. 
In the brains of $\mathrm{AD}$ patients, there is an increase of SET expression $[24,25]$. Interestingly, SET is also translocated from the nucleus to the cytoplasm in the hippocampus and the temporal cortex of AD patients $[25,26]$. We observed that in the CA1 of $\mathrm{AD}$ patients, the translocation of SET to the cytoplasm was associated with an increase of Amyloid Precursor Protein (APP) cleaved in its cytoplasmic domain by a caspase (APPcc) [26]. In in vitro models, cytoplasmic SET is associated with neuronal death [27-29] and with tau hyperphosphorylation [30,31]. The $39 \mathrm{kDa}$ full-length SET can be selectively cleaved resulting in a $\sim 20 \mathrm{kDa}$ fragment in the cytosol of neurons in the brain [25]. The cleavage of SET protein has also been observed in primary neurons treated with kainate and in a mouse model of stroke [32]. This cleavage results from the activation of an asparaginyl endopeptidase (AEP) which cuts SET at asparagine Asn-175, generating NTF and CTF fragments and triggering DNA nicking and cell death [33]. Both NTF and CTF are able to bind to the catalytic subunit of PP2A (PP2Ac) inhibiting its activity and leading to tau hyperphosphorylation [34-36]. However, it is not clear whether the cytoplasmic localization of SET is always associated with its cleavage, with its over-expression, and with tau hyperphosphorylation.

It is still not clear how cytoplasmic SET contributes to PP2A loss of function leading to tau hyperphosphorylation, and whether the presence of SET in the cytoplasm induces low levels of methylated PP2A. We used two models to clarify the relationship between cytoplasmic SET, methylated PP2A, PP2A activity and tau hyperphosphorylation. The first model involved the translocation of endogenous SET from the nucleus to the cytoplasm in primary neurons or brain slices from wild type mice (WT). This translocation was induced in this model by the internalization of the Jcasp peptide. Indeed, this peptide mimics the unmasked juxtamembrane cytoplasmic domain arising from the cleavage of APP by caspases, which is increased in the brains of AD patients [37-39,26]. Moreover, this peptide is sufficient to induce in vivo both translocation of endogenous SET, as occurs in the CA1 of WT mice following APPcc overexpression, and neurodegeneration $[26,27,40]$. The second model involved the over-expression of SET by the internalization of exogenous recombinant full-length protein in brain slices from WT mice [27]. In these two models, we report that cytoplasmic SET induces the hyperphosphorylation of tau in the absence of detectable cleaved forms of SET. We also show that the interaction of SET with PP2A impairs the methylation of PP2A and that the level of methylated PP2A that is associated with the translocation of SET is also negatively correlated with the hyperphosphorylation of tau at Ser-202, but not at Ser-422, suggesting that the hyperphosphorylation of tau is regulated by different mechanisms at distinct residues.

\section{Results}

Internalization of Jcasp peptide induces the translocation of endogenous nuclear SET to the cytoplasm without cleavage or upregulation of its expression

We previously reported that the cytoplasmic internalization of the Jcasp peptide by primary neurons resulted in the translocation of endogenous SET to the cytoplasm and triggered pro-apoptotic signals at the cell membrane $[27,28]$. Thus, in this model, SET promotes apoptosis, and its translocation to the cytoplasm appears to participate in the active neurodegenerative process [27,28].

In this model, we also previously showed that the Jcasp peptide fused to the Penetratin vector is quickly internalized, and that endogenous SET starts to move from the nucleus to the cytoplasm after $3 \mathrm{~h}$, while apoptosis was observed $24 \mathrm{~h}$ later [27]. Here, we show that translocated SET is still present in the cytoplasm of the cellular body and in neurites $5 \mathrm{~h} 30 \mathrm{~min}$ after Jcasp peptide internalization (Figure 1A). Sub-cellular fractionation and western blotting revealed the presence of a $39 \mathrm{kDa}$ band corresponding to endogenous SET in the cytoplasm fraction of cells treated with Jcasp peptide (Figure 1B). The proportion of translocated SET was $39 \%$ of total endogenous SET (Figure 1B), which was in accordance with observations made by epifluorescence microscopy (Figure 1A). Cleavage products of SET in the nucleus and in the cytoplasm were not detected (Figure 1B). Real-time PCR showed that the level of SET transcripts was unchanged during the $5 \mathrm{~h} 30 \mathrm{~min}$ of Jcasp peptide internalization (Figure 1C).

Hence, in this model, the translocation of SET from the nucleus to the cytoplasm does not require its overexpression and/or its cleavage.

\section{Over-expression of recombinant cytoplasmic SET in primary mouse neurons and mouse brain slices does not induce its cleavage}

We introduced a recombinant HA-tagged SET protein fused to the Penetratin vector into the cytoplasm of primary neurons by direct internalization as previously described [27]. We detected the $49 \mathrm{kDa}$ recombinant SET protein by immunocytochemistry with an anti-HA antibody and analyzed its distribution by confocal microscopy. After $3 \mathrm{~h}$ of internalization, the recombinant SET protein, which possesses a nuclear targeting sequence, was mostly concentrated in the cell body around the nucleus and had started to move inside the nucleus (Figure 2A). After 5 h 30 min of internalization, the nucleus was enriched with the recombinant SET protein, although recombinant SET was still abundantly present in the cytoplasm (Figure 2B). We confirmed these observations with mouse brain slices that were treated with the recombinant SET protein. Sub-cellular fractionation followed by western blotting with an anti-HA 


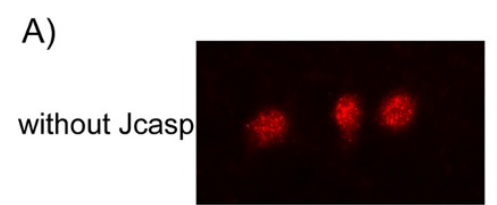

endogenous SET

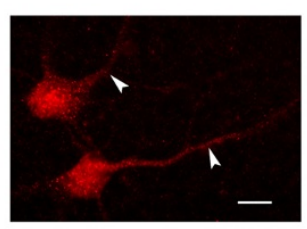

endogenous SET

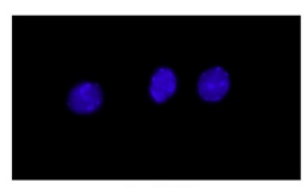

DAPI

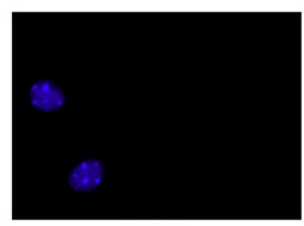

DAPI

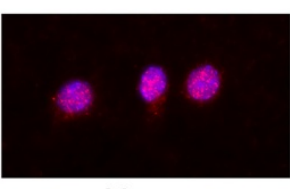

Merge

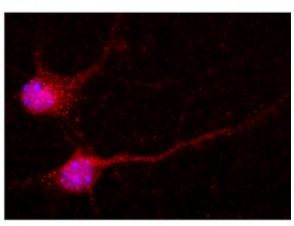

Merge

B)

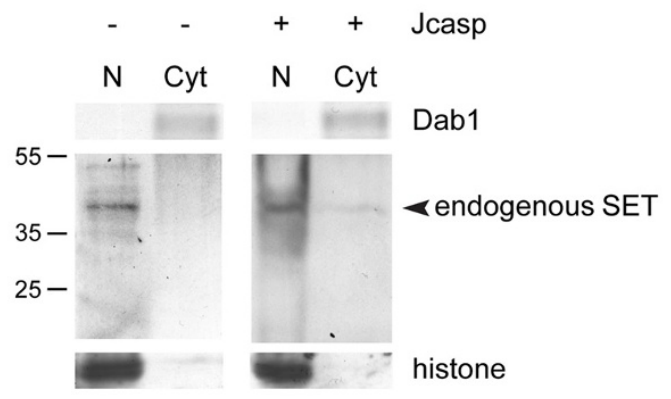

C)

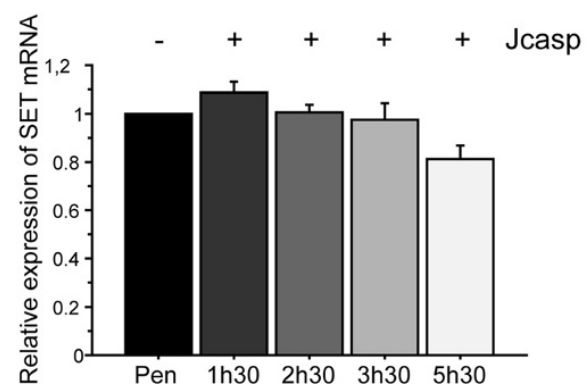

Figure 1 Endogenous SET translocation after $5 \mathrm{~h} 30 \mathrm{~min}$ of Jcasp peptide internalization in mouse primary neurons. A)

Immunocytochemical staining (epifluorescence) of endogenous SET (Cy3) in primary neurons treated with the Jcasp peptide $(2 \mu \mathrm{M})$ for $5 \mathrm{~h}$ $30 \mathrm{~min}$, and control neurons in the absence of any peptide. Nuclei were labeled with DAPI. SET is mostly present in the nucleus of control neurons in the absence of any peptide as indicated in combined images (Merge), whereas SET translocation to the cytoplasm occurs after the internalization of Jcasp peptide (see arrowheads). One representative immunocytochemical staining out of five independent experiments is presented. Scale bar, $10 \mu \mathrm{m}$. B) Representative western blot of cytoplasmic (Cyt) and nuclear (N) neuronal extracts obtained by sub-cellular fractionation ( $n=3$ independent experiments). Endogenous SET was detected with a SET antibody. Dab1 was used as a cytoplasmic control and histone was used as a nuclear control. A total of $10 \mathrm{\mu g}$ of protein was loaded in each lane. Endogenous SET at $39 \mathrm{kDa}$ is partially localized in the cytoplasm in cells containing Jcasp peptide. Cleaved SET fragments cannot be detected. C) Relative expression of SET mRNA assessed by quantitative real-time PCR in cells treated with Jcasp peptide for $1 \mathrm{~h} 30 \mathrm{~min}, 2 \mathrm{~h} 30 \mathrm{~min}, 3 \mathrm{~h} 30 \mathrm{~min}$ and $5 \mathrm{~h} 30 \mathrm{~min}$ and with the Penetratin (Pen) peptide only at the same time points. Results are expressed as the ratio of SET mRNA in Jcasp peptide internalization versus Penetratin only assays at the different time points. Data presented are the mean \pm SEM of three independent experiments. Jcasp peptide does not affect the level of SET mRNA.

antibody revealed the presence of recombinant SET in the cytoplasm (Figure 2C-F). The detected bands of low molecular weight and low intensity were unspecific bands resulting from the anti-rabbit secondary antibody (Figure 2F). We did not observe cleaved recombinant SET protein in either sub-cellular compartment studied (Figure 2E).
Interaction between uncleaved cytoplasmic recombinant SET protein and PP2A inhibits the activity of PP2A and impairs its methylation in the brain slices of adult mice Following its translocation to the cytoplasm, endogenous SET interacts with the catalytic subunit of PP2A inducing its inhibition [23,34]. We used direct internalization for $5 \mathrm{~h} 30 \mathrm{~min}$ to overexpress recombinant SET protein 


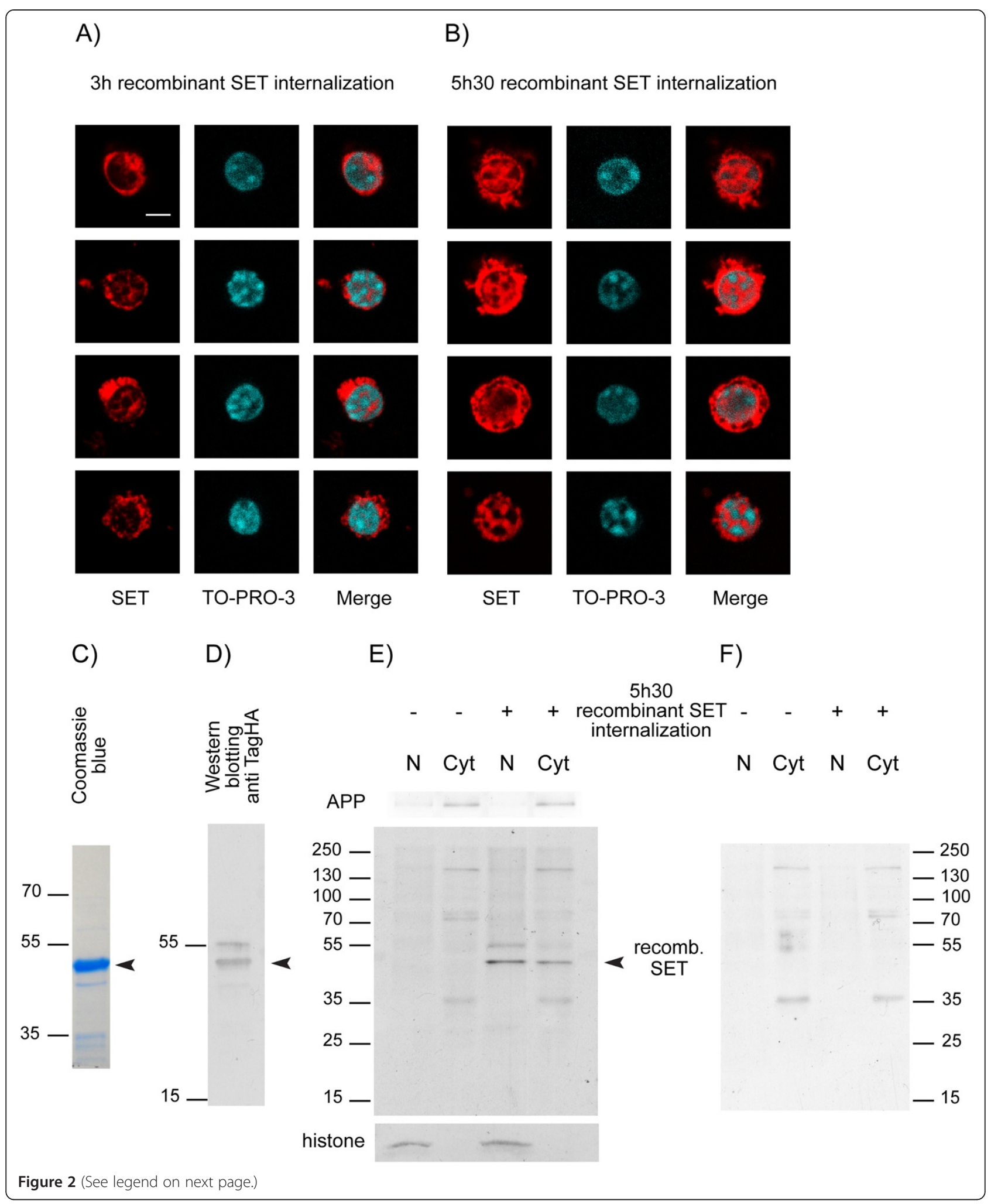


(See figure on previous page.)

Figure 2 Localization of the recombinant SET protein after its internalization. Recombinant SET protein $(4 \mu \mathrm{M})$ was internalized for $3 \mathrm{~h}$ and $5 \mathrm{~h} 30 \mathrm{~min}$ in mouse primary neurons (A, B) and for $5 \mathrm{~h} 30 \mathrm{~min}$ in mouse brain slices (E, F). Confocal microscopy shows immunocytochemical staining of recombinant SET carried-out with an anti-tag HA antibody. Nuclei were labeled with TO-PRO-3. Four examples at $3 \mathrm{~h}$ (A) and at $5 \mathrm{~h}$ $30 \mathrm{~min}$ (B) are shown. At $3 \mathrm{~h}$, recombinant SET protein is mostly located in the cytoplasm around the nucleus, whereas at $5 \mathrm{~h} 30$ min SET is distributed in both the cytoplasm and nucleus. One representative immunocytochemical staining out of three independent experiments is presented. Scale bar, $10 \mu \mathrm{m}$. (C) Electrophoresis of tag-HA recombinant SET protein (10 $\mathrm{\mu g}$ of protein was loaded). Coomassie blue shows a major band at $49 \mathrm{kDa}$, as expected. D-F) Tag-HA recombinant SET protein $(0.4 \mu \mathrm{g})$ was detected by western blotting with a tag-HA antibody (D). Sub-cellular fractions were prepared from brain slices treated for $5 \mathrm{~h} 30 \mathrm{~min}$ with recombinant SET protein and $10 \mu \mathrm{g}$ of proteins were loaded in each lane. Recombinant SET was detected with a tag-HA antibody (E). APP was used as a cytoplasmic (Cyt) control and histone was used as a nuclear (N) control. Recombinant full-length SET protein is observed at $49 \mathrm{kDa}$ in nuclear and cytoplasmic fractions as in (B). Unspecific bands recognized by the secondary antibody are shown in (F). For (D-F), one representative immunoblot out of five independent experiments is shown and for (C), one protein staining of recombinant SET out of three independent experiments is presented (C).

$(4 \mu \mathrm{M})$ in adult mouse brain slices maintained under oxygenation conditions, as described in Methods. We first analyzed total phosphatase activity (Figure $3 \mathrm{~A}$ ). We used okadaic acid (OA), a marine sponge toxin which is an inhibitor of PP2A, as a positive control $(1 \mu \mathrm{M}$ for $2 \mathrm{~h})$ [41]. OA inhibited total phosphatase activity by $33.6 \% \pm$ $3.7 \%(\mathrm{n}=11)$ and recombinant SET inhibited total phosphatase activity by $13.1 \% \pm 3.3 \%(n=11)$. Hence, phosphatase activity was significantly impaired in both cases and was $68.4 \% \pm 3.7 \%$ of the baseline value (standardized to $100 \%)$ for OA $(\mathrm{n}=11, p<0.0001)$, and was $86.9 \% \pm$ $3.3 \%$ for recombinant SET $(\mathrm{n}=11, p=0.0008)$ (Figure 3A). We then evaluated PP2A activity (which represents 70\% of total phosphatase activity [42]) after PP2A immunoprecipitation in brain slices treated with $\mathrm{OA}$ and in those containing internalized recombinant SET protein. The remaining PP2A activity was $33.8 \% \pm 9.8 \%(\mathrm{n}=3$, $p=0.0025)$ in brain slices treated with $\mathrm{OA}$ and $84 \% \pm$ $3.8 \%$ in brain slices containing recombinant SET $(\mathrm{n}=3$, $p=0.0124$ ) (Figure 3B). These values fit with what we observed for total phosphatase activity. Thus, these data suggest that when SET is in the cytoplasm, it specifically impairs PP2A activity in a manner that does not depend on its cleavage (Figure 2E).

The activity of PP2A depends on its methylation [7-10]. Therefore, we assessed whether the interaction between cytoplasmic recombinant SET protein and endogenous PP2A impaired the methylation of PP2A, resulting in a decrease in its activity. We used an antibody directed against total PP2A (methylated and not methylated) and an antibody specifically directed against methyl-PP2A, and evaluated the ratio of methyl-PP2A to total PP2A by western blotting (Figure 3C, D). After 5 h 30 min of recombinant SET protein internalization, the ratio of methyl-PP2A to total PP2A was $83.6 \% \pm 5.2 \%(\mathrm{n}=9)$ of the control ratio (standardized to 100\%) in the absence of recombinant SET (Figure 3D). The mean decrease of this ratio $(16.4 \%)$ was significant $(p=0.0057)$ suggesting that the presence of SET in the cytoplasm in the absence of detectable SET cleavage impairs the methylation of PP2A.

Finally, we performed co-immunoprecipitation experiments to check that the internalized recombinant SET protein interacted with PP2A and impaired the methylation of PP2A. To this end, we internalized the recombinant SET protein in brain slices for $5 \mathrm{~h} 30 \mathrm{~min}$, and we extracted proteins from these slices and from control slices not internalized with recombinant SET. After lysis, we checked first the total level of PP2A (Figure 3E, lanes 1,2) and methyl-PP2A (Figure 3E, lanes 7, 8) in brain slices by western blotting. We subsequently immunoprecipitated SET from slice extracts with an antibody that recognizes both endogenous and recombinant SET. We then analyzed the immunoprecipitates by western blotting with an antibody that recognizes total PP2A (Figure 3E, lanes 3-6) and after membrane stripping, with an antibody that specifically recognizes methyl-PP2A (Figure 3E, lanes 9-12). Only a small amount of PP2A co-immunoprecipitated with the SET antibody (Figure 3E, lane 4) in extracts from brain slices lacking recombinant SET, because only a small proportion of endogenous SET is cytoplasmic. More PP2A co-immunoprecipitated with SET in cells containing recombinant SET protein than in cells lacking the recombinant protein (Figure 3E, lane 6), showing that PP2A can bind to both recombinant and endogenous SET protein. In contrast, more methyl-PP2A co-immunoprecipitated with SET in the control (Figure 3E, lane 10) than in cells containing recombinant SET protein (Figure 3E, lane 12). The mean ratio of methyl-PP2A to total PP2A was $2.18 \pm$ $0.22(\mathrm{n}=3)$ for the control (Figure 3E, lane 10 to lane 4) and $0.59 \pm 0.10$ for brain slices treated for $5 \mathrm{~h} 30 \mathrm{~min}$ with recombinant SET protein (Figure 3E, lane 12 to lane 6). Thus, the level of co-immunoprecipitated methylated PP2A was significantly lower in slices internalized with SET protein than in the control $(p=0.0027)$ (Figure 3F). These data confirm that cytoplasmic, uncleaved, recombinant SET protein interacts with PP2A and impairs its methylation. 
A)

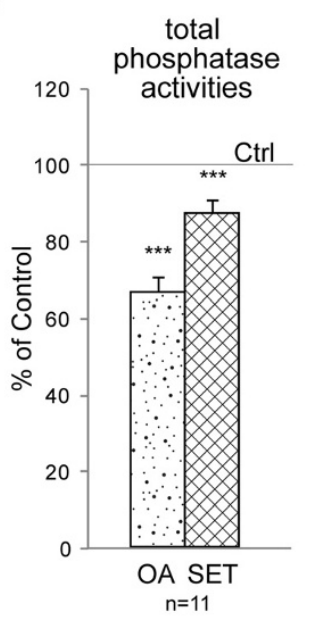

C)

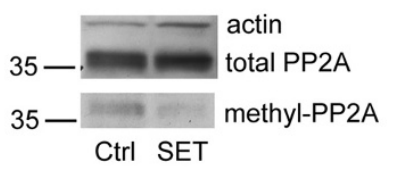

B)

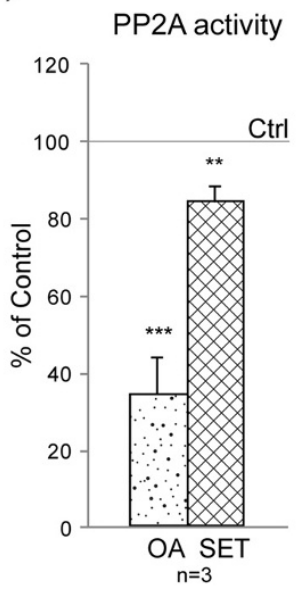

D)

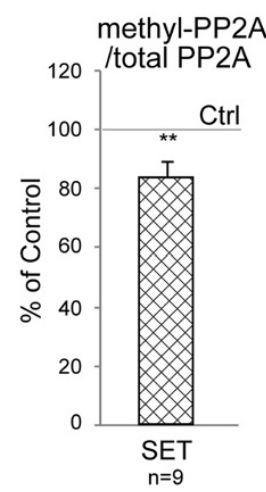

E)

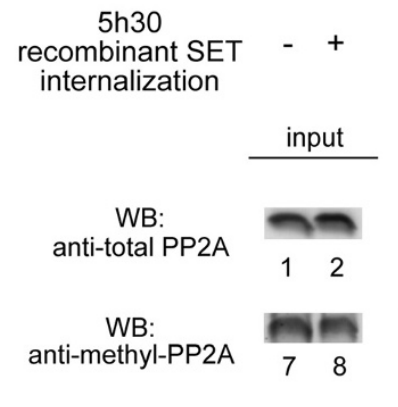

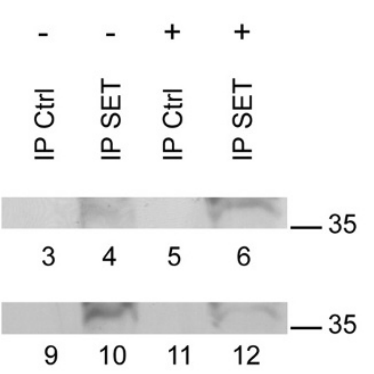

F)

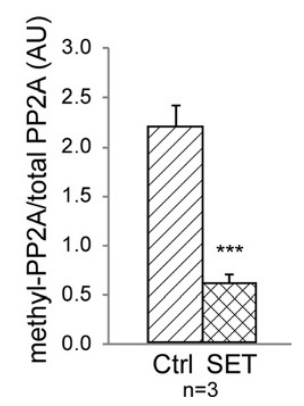

Figure 3 Phosphatase activities and PP2A methylation in adult mouse brain slices treated with recombinant SET protein for 5 h 30 $\mathrm{min}$. A) The release of $\mathrm{p}$-nitrophenol (nmoles of $\mathrm{p}$-nitrophenol/mg of protein) was assessed. Results are expressed as a percentage of control (Ctrl) activity that was set to 100\%. Mean \pm SEM of 11 independent experiments; okadaic acid (OA); OA versus Ctrl: $p<0.0001$; SET versus Ctrl: $p=0.0008$. B) Release of $p$-nitrophenol measured on immunoprecipitated PP2A. Mean \pm SEM of three independent experiments; OA versus Ctrl: $p=0.0025$; SET versus Ctrl: $p=0.0124$. C) Representative western blot ( $40 \mu \mathrm{g}$ of protein loaded) of total and methylated PP2A (methyl-PP2A) and quantification of the ratio of methylated PP2A to total PP2A D). Mean \pm SEM of nine independent experiments. SET versus Ctrl: $p=0.0057$. E) Representative western blot of total PP2A and methyl-PP2A co-immunoprecipitated with a SET primary antibody (out of three independent experiments). Mouse brain slices in the absence $(-)$ or the presence of recombinant SET protein $(+)$ were immunoprecipitated with a SET antibody. Co-immunoprecipitated proteins were analyzed by western blotting, with a total PP2A antibody (lanes 3-6) and with a methylated PP2A (methyl-PP2A) antibody after membrane stripping (lanes 9-12). PP2A (lanes 3 and 5) and methyl-PP2A (lanes 9 and 11) are not detectable in absence of primary SET antibody (IP Ctrl). Similar levels of total PP2A (lanes 1 and 2) and methyl-PP2A (lanes 7 and 8) in total extracts before SET immunoprecipitation. F) Quantification of the ratio of methyl-PP2A to total PP2A co-immunoprecipitated with SET primary antibody in mouse brain slices treated with recombinant SET protein for 5 h 30 min and control (Ctrl) brain slices (no internalization). Meam \pm SEM of three independent experiments; SET versus Ctrl: $p=0.0027$. 


\section{Uncleaved SET in the cytoplasm induces hyper- and abnormal phosphorylation of tau protein. Correlation with decreased methyl-PP2A levels}

Many phosphorylation sites of tau in paired helical filaments (PHF) have been identified in the brains of $\mathrm{AD}$ patients [1-3]. Inhibition of PP2A leads to the preferential hyper-phosphorylation of tau at various epitopes. Phosphorylation at Ser-202 and Ser-404 is more prevalent in PHF-tau and fetal tau than in normal adult tau $[43,44]$; therefore, we analyzed hyper-phosphorylation of tau at both these sites. We then focused on Ser-202 because PP2A alone regulates dephosphorylation at this site [44]. We used the AT8 antibody, which is commonly used for the immunohistological analysis of $\mathrm{AD}$ patient brains. This antibody can recognize monophosphorylated tau at Ser-202 [45]. We also focused our analysis on the abnormal phosphorylation at Ser-422, because the phosphorylation of this site is observed only in PHF-tau and is almost undetectable in biopsy-derived adult human tau [46].

We prepared lysates from brain slices internalized with Jcasp peptide or recombinant SET protein for $5 \mathrm{~h}$ $30 \mathrm{~min}$ and analyzed tau phosphorylation by western blotting with various antibodies (see Methods) directed against the epitopes mentioned above. We used OA, which increases tau phosphorylation at several physiological sites and induces phosphorylation at abnormal sites, as a positive control. We used the JA peptide as a negative control; this peptide is a mutated form of the Jcasp peptide in which a tyrosine is replaced with an alanine resulting in a peptide that induces neither the deleterious effect of the Jcasp peptide nor SET translocation $[40,27]$. We observed an increase of phosphorylated tau in cells containing the Jcasp peptide or recombinant SET protein (Figure 4A) whereas tau phosphorylation in cells containing the JA peptide was similar to that of the control. We defined tau phosphorylation of the control as $100 \%$. Hyper-phosphorylation at Ser-202 that was induced by the recombinant SET protein was $177.6 \pm 27.1 \%$ $(\mathrm{n}=8 ; p=0.02)$, and that induced by recombinant SET at Ser-422 was $148.3 \pm 27.3 \%(n=7)$ (Figure $4 B)$. However the hyperphosphorylation at Ser-422 was lower than that at Ser-202, except for one animal out of the seven studied. The hyper- and/or abnormal phosphorylation of tau protein induced by recombinant SET protein or Jcasp peptide usually involve the same tau protein isoforms as those affected by OA. However, in some experiments, the isoforms affected by OA differed from those affected by recombinant SET protein or the Jcasp peptide, as observed for the $50 \mathrm{kDa}$ tau isoform at Ser-404 (Additional file 1: Figure S1A), Ser-356, and Ser-235 (Additional file 1: Figure S1A) and the $70 \mathrm{kDa}$ tau isoform at Ser-202 (Additional file 1: Figure S1B). The level of PP2A was similar in all conditions (Figure 4A). Interestingly, we found a significant negative correlation between the percentage of methylated PP2A and the percentage of tau protein hyper-phosphorylated at Ser-202 that was detected with the AT8 antibody $\left(R^{2}=0.89, n=7\right)$ (Figure $\left.4 C\right)$. However, there was no correlation with the percentage of tau protein abnormally phosphorylated at Ser- $422\left(R^{2}=-0.06\right.$, $\mathrm{n}=7$ ) (Figure 4D), confirming that PP2A preferentially acts on the phosphorylation of tau at Ser-202.

\section{Discussion}

We report here that the presence of SET in the cytoplasm, in absence of its over-expression or cleavage, decreases the activity of PP2A and thus stimulates tau hyperphosphorylation. Cytoplasmic SET impairs the methylation of PP2A, and the level of methylated PP2A is negatively correlated with tau hyperphosphorylation at Ser-202 but not at Ser-422.

An increase of SET expression leading to an increase of SET protein has been described in the brains of $\mathrm{AD}$ patients, and is associated with the cytoplasmic translocation of SET [25]. More recently, we also observed an increase of SET associated with its cytoplasmic translocation in the hippocampus of Down syndrome patients and in the CA1 of AD patients [26]. However, we cannot exclude that particular stress signals trigger the delocalization of SET in the absence of its over-expression in some subregions of the brains of $\mathrm{AD}$ patients [26]. The translocation of endogenous SET was induced by a cell death signal in the Jcasp model [28] in absence of SET over-expression. Similarly, we reported that the over-expression of APPcc with a lentiviral construct in the CA1 of mice resulted in the translocation of endogenous SET in the absence of SET increase [26]. Phosphorylation of SET at Ser-9 by casein kinase II causes the cytoplasmic retention of SET in the neuronal cytoplasm of the brains of AD patients [47]. We did not investigate the phosphorylation of SET at Ser-9 following the translocation of SET from the nucleus to the cytoplasm, or after its uptake by neurons.

The role of SET cleavage is not clear. Full-length SET and its cleaved forms can bind to PP2A, inhibiting its activity and thus increasing tau phosphorylation [34]. It is not clear whether this cleavage occurs in the nucleus or in the cytoplasm and whether both fragments remain in the same subcellular compartment. However, transfection experiments show that full-length SET is found within the nucleus as expected, whereas the NTF is distributed across cell compartments and the CTF is concentrated in the nucleus but is also present in the cytoplasm [34]. A recent report showed that the level of asparaginyl endopeptidase, which cleaves SET at Asn-175, is increased in the brains of $\mathrm{AD}$ patients [33]. Moreover, asparaginyl endopeptidase translocates from neuronal lysosomes to the cytoplasm where SET can be cleaved, an event that was observed under acidic conditions in vitro and ex vivo 


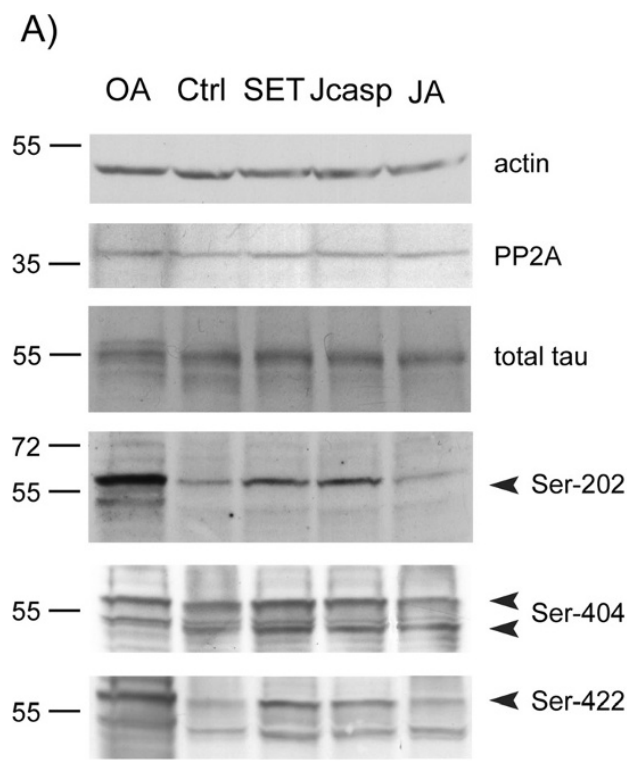

C)

Ser-202

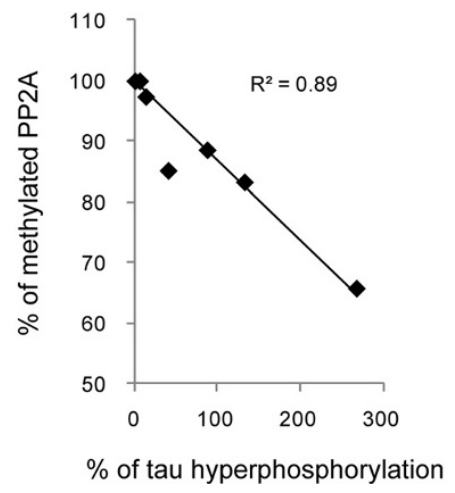

B)

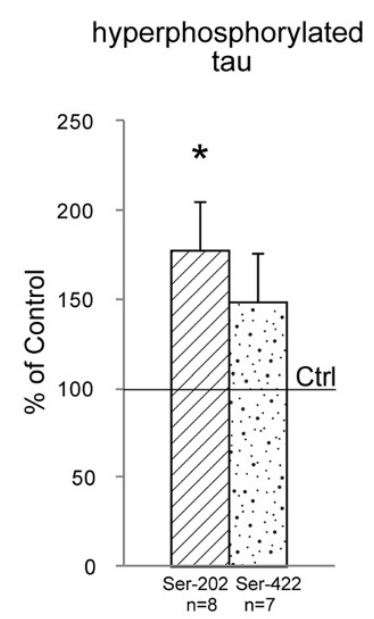

D)

Ser-422

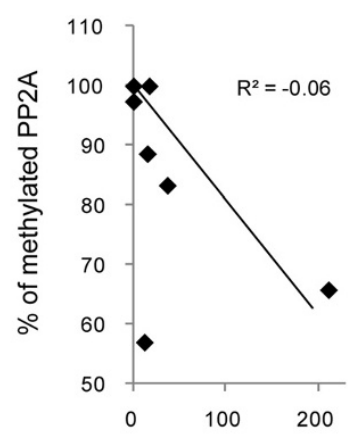

$\%$ of tau hyperphosphorylation

Figure 4 Phosphorylation of tau in adult mouse brain slices treated with recombinant SET protein or Jcasp peptide for $5 \mathrm{~h} 30$ min and its relationship with methylated PP2A. A) Proteins were extracted from mouse adult brain slices treated with recombinant SET protein or Jcasp peptide and were analyzed by western blotting (40 $\mathrm{mg}$ per lane). Representative western blots of tau hyperphosphorylation at Ser-202, Ser-404 and Ser-422 and total tau protein are shown. Brain slices not treated with any protein (Ctrl) and brain slices treated with mutated Jcasp (JA) were used as negative controls. Okadaic acid (OA) was used as positive control. PP2A was also analyzed. Actin was used as internal loading control. Jcasp or SET internalization induces hyperphosphorylation of the same tau isoforms. B) Quantification of hyperphosphorylation of Ser-202 ( $n=8$ independent experiments) and Ser-422 ( $n=7$ independent experiments) in brain slices treated with SET relative to the phosphorylation of tau at these residues in control cells (set to 100\%). Results were normalized to total tau. C-D) Correlation between tau hyper-phosphorylation at Ser-202 (C) ( $n=8$ independent experiments) and Ser-422 ( $n=7$ independent experiments) (D) and methylated PP2A. Phosphorylation at Ser-202 is significantly negatively correlated with methylated PP2A in cells containing recombinant SET.

[33]. The absence of acidic conditions in the ex vivo models used in this report may explain why SET was not cleaved. We cannot exclude that SET is somewhat cleaved in in vivo conditions. Nonetheless, we show that cytoplasmic, full-length SET is sufficient to decrease PP2A activity and induce tau hyperphosphorylation, regardless of the route of entry of SET to the cytoplasm.

Caspases cleave APP at Asp-664 (APPcc). An increase of APPcc has already been shown in the brains of AD patients [37-39]. APPcc may be cleaved further into amyloid peptide resulting in the release of fragments containing the Jcasp sequence. APP intracellular domain generated after amyloid formation, can also be cleaved by caspases, leading to the formation of analogs of the Jcasp sequence. We found that the delivery of the Jcasp peptide to the cytoplasm was sufficient to induce the translocation of SET and the hyper-phosphorylation of tau, similar to what we observed with the over-expression of APPcc [26]. Recently, Asp-664 cleavage of APP in N2A cells and primary hippocampal neurons was shown to 
induce tau hyperphosphorylation by decreasing PP2A activity [48].

The activity of PP2A is low in the brains of AD patients [12-14]. Specific inhibitors of PP2A such as I1PP2A and SET, if localized in the cytoplasm, may underlie this impaired activity. The low activity of PP2A in the brains of $\mathrm{AD}$ patients may be also partly related to the low level of PP2A methylated at Leu-309 of the PP2Ac $[15,17]$. The methylation of this residue is also impaired in the cortex of transgenic APPxPS1 mice, in the brains of mice with mutated estrogen receptors, and after the treatment of N2A cells carrying the human APP Swedish mutation with OA [17]. We report here that full-length SET in the cytoplasm interacts with PP2A and decreases its methylation, thus impairing PP2A activity that leads to tau hyper-phosphorylation. Our co-immunoprecipitation experiments confirm the interaction of PP2A with fulllength SET that was reported previously [34]. This interaction may impair the methylation of PP2A by inducing a conformational change that either prevents the interaction of PP2A with the leucine carboxyl methyltransferase 1 or stimulates its interaction with the PP2A specific methylesterase PME-1 [49-51]. Alternatively, the interaction of PP2A with SET may lead to a change of localization of PP2A, which may be preferentially redistributed to nonraft membrane domains where PP2A methylesterase PME-1 is exclusively present [51].

The physiological cellular state of phosphorylation results from an equilibrium between phosphatases and kinases. Dephosphorylation at Ser-202 and Ser-422 is dependent on PP2A [3]. Interestingly, we established a negative correlation between the level of methylated PP2A and that of tau phosphorylated at Ser-202, confirming that the phosphorylation of the Ser-202 site is directly dependent on PP2A activity $[52,44]$. This also suggests that SET, via the methylation of Leu-309 in PP2Ac, plays an important role in phosphorylation at Ser-202, which is consistently detected in the brains of $\mathrm{AD}$ patients. In contrast, we did not observe a negative correlation between the level of methylated PP2A and tau hyperphosphorylation at Ser-422, despite the fact that dephosphorylation at this site depends on PP2A. This suggests that the demethylation of PP2A that is induced by SET does not substantially affect tau phosphorylation at Ser-422. In addition to methylation, PP2A activity can be modulated by other post-translational modifications. We cannot exclude that the interaction of SET with PP2A additionally results in the phosphorylation of PP2A which may be negatively correlated with the phosphorylation of Ser-422. PP2A is phosphorylated at Tyr-307 in PP2Ac by a scr kinase, and this phosphorylated form is also detected in the brains of $\mathrm{AD}$ patients [11]. Phosphorylation at this residue or at Ser-41 in the $56 \alpha$ subunit, which is mediated by a $\mathrm{PKC} \alpha$, impairs
PP2A activity [53]. In our models, we do not know whether SET induces such post-translational modifications contributing to the impairment of PP2A activity.

PP2A dephosphorylates tau, which leads to the stimulation of several tau kinases [53,54]. In our study, cytoplasmic SET inhibited PP2A; thus, the subsequent tau hyperphosphorylation observed was the result of the absence of tau dephosphorylation. Our data show that Ser-202 becomes highly phosphorylated when cytoplasmic SET inhibits PP2A activity, in contrast with the low phosphorylation at Ser-422 in most studies. However, phosphorylation at Ser-422 is almost undetectable in humans at the adult stage, emphasizing the relevance of a low detectable phosphorylation, as observed in the brains of AD patients [46]. Ser-202 is principally dependent on GSK3- $\beta$ [44] whereas Ser-422 is a good substrate for MAP kinase but not for GSK3- $\beta$ [46], suggesting that different sites of tau phosphorylation are regulated by specific kinases. Consequently, cytoplasmic SET, via its inhibition of PP2A would be differently involved in the regulation of specific sites of phosphorylation.

In mouse brain slices, we used OA, which is an exogenous natural inhibitor of phosphatases that inhibits $70 \%$ of PP2A activity, as a positive control of tau phosphorylation. In some cases, the pattern of the tau isoforms that were hyperphosphorylated by endogenous cytoplasmic SET or cytoplasmic recombinant SET protein differed from that observed with OA (Figure 4A and Additional file 1: Figure S1), which highlights the physiological relevance of our models. Moreover, both recombinant SET protein and the Jcasp peptide stimulated the hyperphosphorylation of the same tau isoforms (Figure 4A and Additional file 1: Figure S1), which shows that this Jcasp peptide that mimics the unmasked domain of APP after caspase cleavage may be a relevant model for physiopathological investigations of APPcc. In our ex vivo model, recombinant SET protein was successfully internalized in the cytoplasm of adult mouse brain slices, where it impaired PP2A methylation and consequently PP2A activity, leading to an accumulation of hyperphosphorylated tau. This model may be used to test molecules that may disrupt the interaction of SET with PP2A and thus prevent the inhibition of PP2A activity [55].

Overall, these data suggest that when SET is in the cytoplasm, it reproduces tau hyperphosphorylation observed in the brains of $\mathrm{AD}$ patients by impairing the methylation of PP2A. These findings highly implicate cytoplasmic SET in the progression of the disease.

\section{Conclusion}

We used two ex vivo models to show that full-length, cytoplasmic SET, independent of its cleavage, inhibits PP2A activity by decreasing its methylated form, which leads to tau hyperphosphorylation. These findings link 
the decrease of methylated PP2A (and hence the decrease of PP2A activity) to the translocation of SET to the neuronal cytoplasm, which are two events that are observed in the brains of $\mathrm{AD}$ patients. In addition, the negative correlation between the level of methylated PP2A and some, but not all, sites of phosphorylation in tau suggests that tau phosphorylation is regulated by several mechanisms. These data provide an important contribution to the elucidation of the mechanisms involved in AD.

\section{Methods}

\section{Antibodies}

The various antibodies were purchased and diluted as follows.

Anti-Disabled-1, AB5840 (Millipore, Saint Quentin en Yvelines, France) polyclonal rabbit antibody, diluted to 1/1000 for western blotting; anti-I2PP2A/SET (H-120), sc-25564 (Santa Cruz Biotechnology, Heidelberg, Germany) affinity purified rabbit polyclonal IgG for endogenous SET analysis, diluted to $1 / 2000$ for western blotting, to $1 / 100$ for immunocytochemistry, and to $1 / 100$ for SET immunoprecipitation; anti-Histone clone H11-4, MAB 3422 (Millipore) purified mouse monoclonal IgG1, diluted to $1 / 100$ for western blotting; anti-HA mouse monoclonal antibody MMS 101R (Covance, Eurogentecs, Angers, France), for recombinant SET protein analysis, diluted to $1 / 1000$ for western blotting and to $1 / 200$ for immunocytochemistry; anti-APP-Nter anti-Alzheimer Precursor Protein A4 clone 22C11 MAB 348 (Millipore) mouse monoclonal antibody, diluted to $1 / 1000$ for western blotting; anti-Actin, clone C4 MAB 1501R (Millipore) mouse monoclonal antibody, diluted to $1 / 10000$ for western blotting; anti-PP2A C subunit clone 1D6 05-421 (Millipore) mouse monoclonal antibody, diluted to $1 / 2000$ for total protein phosphatase $2 \mathrm{~A}$ western blotting analysis; antimethyl-PP2A C subunit clone 2A10 04-1479 (Millipore) mouse monoclonal antibody, diluted to $1 / 1000$ for western blotting; anti-p-Tau (Ser 404) sc-12952 (Santa Cruz Biotechnology) rabbit polyclonal affinity purified antibody, diluted to 1/500 for western blotting; anti-p-Tau (Ser 235) sc-101812 (Santa Cruz Biotechnology) rabbit polyclonal antibody, diluted to $1 / 500$ for western blotting; anti-Tau (pSer356) 54975 (AnaSpec, San José, CA, USA) rabbit polyclonal antibody, diluted to $1 / 100$ for western blotting; anti-Tau (phospho S422) ab4862 (Abcam, Cambridge, UK), rabbit polyclonal antibody diluted to 1/1000 for western blotting; anti-p-Tau (Ser202), antiHuman PHF-TAU clone AT8 BR-03 (Innogenetics, Courtaboeuf, France) mouse monoclonal antibody, diluted to 1/1000 for western blotting; anti-Tau mouse (TAU-5) mAb 577801 (Calbiochem, Merck Chemicals Limited, Nottingam, UK) mouse monoclonal antibody, diluted to $1 / 1000$ for total tau analysis in western blotting.
The secondary HRP-antibodies used for the detection of chemiluminescence were Goat anti-mouse $\operatorname{IgG}(\mathrm{H}+\mathrm{L})$ HRP conjugate 170-16516 (Bio-Rad, Marnes-La-Coquette, France), diluted to $1 / 5000$ and ECL anti-rabbit IgG-HRP NA9340V (GE Healthcare, Dutscher, Brumath, France) diluted to $1 / 2000$.

Secondary antibodies used for immunocytochemistry were Donkey anti-rabbit cy3 diluted to $1 / 500$ and Donkey anti-mouse cy3 diluted to $1 / 200$ (both from Jackson Immuno-research, Interchim, Montluçon, France).

\section{Jcasp, JA peptides and recombinant SET protein}

Peptides of APP 649-664 (Jcasp) and Y653A Jcasp (JA) both containing penetratin at their $\mathrm{N}$-termini were chemically synthesized (95-98\% purity, Neomps, Strasbourg, France).

Recombinant SET protein was synthesized as previously described [27].

\section{Ethics statement}

All animal procedures were carried out according to French and European Union regulations. The protocols of animal anesthesia were performed according to the recommendations of the European Economic Community (86/609/EEC) and the French National Committee (87/ 848) of the French government and were approved by the local ethics committee (Direction départementale des services vétérinaires de Paris, service de la protection et santé animales et de la protection de l'environnement).

\section{Primary cortical neurons}

Primary cortical neurons were obtained from E16 Swiss mouse embryos, as described previously [56]. Dissociated cells were plated on polyornithine-coated plastic dishes for biochemical analysis and on glass coverslips for immunocytochemistry at a density of $15 \times 10^{4} \mathrm{cells} / \mathrm{cm}^{2}$. The Jcasp peptide or its mutant JA peptide $(2 \mu \mathrm{M}$ final concentration) or the recombinant SET protein $(4 \mu \mathrm{M}$ final concentration) were added to the culture medium at 5 days in vitro (DIV) and were incubated for $3 \mathrm{~h}$ or $5 \mathrm{~h}$ $30 \mathrm{~min}$.

\section{Ex vivo adult mouse brain slices}

Male Swiss mice were killed by decapitation and the brains were put on ice. The cerebellum, olfactory bulb, and thalamus were discarded. Cross sections of brain hemispheres were then rapidly cut at $4^{\circ} \mathrm{C}$ with a McILwain tissue chopper. Slices (300 $\mu \mathrm{m}$ thick) were suspended in $10 \mathrm{ml}$ of modified Krebs-Ringer phosphate medium (KPR) $\left(\mathrm{NaCl} 123 \mathrm{mM}, \mathrm{KCl} 2 \mathrm{mM}, \mathrm{CaCl}_{2} 2.6 \mathrm{mM}, \mathrm{MgSO}_{4}\right.$ $0.67 \mathrm{mM}, \mathrm{KH}_{2} \mathrm{PO}_{4} 1.2 \mathrm{mM}$, Glucose $5.9 \mathrm{mM}$ and $\mathrm{NaHCO}_{3} 27 \mathrm{mM}$ ) that was equilibrated to $\mathrm{pH} 7.4$ with a mixture of $\mathrm{O}_{2} / \mathrm{CO}_{2}(95 / 5)$ at room temperature for $30 \mathrm{~min}$, as previously described [57]. The slices were 
then washed 3 times for $10 \mathrm{~min}$ each. The slices were finally resuspended in $3 \mathrm{ml}$ of fresh KPR and were incubated in a water bath at $37^{\circ} \mathrm{C}$ for 15 min under a constant flow of $\mathrm{O}_{2} / \mathrm{CO}_{2}(95 / 5)$. The slices were then homogeneously distributed into 4 well culture dishes (about 16 wells for one mouse brain per experiment) that were put in a large box placed in a water bath at $37^{\circ} \mathrm{C}$ under a constant flow of $\mathrm{O}_{2} / \mathrm{CO}_{2}$. OA, Jcasp and JA peptides, and recombinant SET protein were added to wells at final concentration of $1 \mu \mathrm{M}, 2 \mu \mathrm{M}, 2 \mu \mathrm{M}$, and $4 \mu \mathrm{M}$, respectively and were incubated at $37^{\circ} \mathrm{C}$ for $2 \mathrm{~h}(\mathrm{OA})$ or $5 \mathrm{~h} 30 \mathrm{~min}$ (Jcasp, JA and SET). At the end of incubation the brain slices were distributed in eppendorf tubes, and were rinsed by decantation three times with the KPR medium to eliminate all traces of OA, Jcasp, JA and SET. Slices were then homogenized with a tissue grinder (Kontes glass $\mathrm{CO}$ ) in different lysis buffers according to the type of analysis. Protein concentration was determined with the Micro BCA Protein Assay Kit (Fischer Scientific, Illkirsch, France).

Slices dedicated to the analysis of tau phosphorylation by western blotting were extracted in Dulbecco's PBS containing DNaseI $(30 \mu \mathrm{g} / \mathrm{ml}), 1 \%$ Triton X-100, protease inhibitors (Complete, Roche Diagnostics, Mannheim, Germany) and phosphatase inhibitors (2 $\mathrm{mM} \mathrm{Na}_{3} \mathrm{VO}_{4}$ and $100 \mathrm{mM} \mathrm{NaF}$ ).

For the analysis of phosphatase 2A (PP2A) activity after PP2A immunoprecipitation, the same extraction buffer without phosphatase inhibitors was used.

For the analysis of total phosphatase activity, slices were rinsed twice in $50 \mathrm{mM}$ Tris buffer, $0.1 \mathrm{mM} \mathrm{CaCl}_{2}$ $\mathrm{pH} 7.5$ containing protease inhibitors and were extracted in the same buffer.

For SET and PP2A co-immunoprecipitation experiments, slices were washed three times in KPR containing protease and phosphatase inhibitors.

\section{Nuclear and cytoplasmic fractionation}

Mouse cortical primary neurons (5 DIV) were incubated with Jcasp peptide $(2 \mu \mathrm{M})$ and mouse brain slices were incubated with either Jcasp peptide $(2 \mu \mathrm{M})$ or recombinant human SET protein $(4 \mu \mathrm{M})$ for $5 \mathrm{~h} 30 \mathrm{~min}$. Primary neurons and mouse brain slices that were not incubated with any peptide or recombinant protein under the same conditions were used as controls. Cells and tissue slices were rinsed once in cold phosphate buffer saline PBS before being subjected to sub-cellular fractionation. $\mathrm{Nu}$ clear and cytoplasmic fractionation was carried out with the Nuclei EZ Prep Nuclei Isolation Kit (Sigma-Aldrich, Saint-Louis, MO, USA) following manufacturer's instructions. Briefly, scrapped neurons and brain slices were lysed in cold Nuclei EZ lysis buffer containing protease inhibitors. The homogenised extracts were incubated on ice for $5 \mathrm{~min}$ and were then centrifuged for $15 \mathrm{~min}$ at $500 \times \mathrm{g}$ at $4^{\circ} \mathrm{C}$. The supernatants were immediately transferred to clean tubes and centrifuged twice for $15 \mathrm{~min}$ at $5000 \times \mathrm{g}$. The final clarified supernatant corresponding to the cytoplasmic fractions were stored at $-80^{\circ} \mathrm{C}$ until use for western blotting. In parallel, the pelleted nuclei were washed in $4 \mathrm{ml}$ of ice cold Nuclei EZ lysis buffer and then were resuspended carefully and incubated for $5 \mathrm{~min}$ on ice. Washed nuclei were then collected by centrifugation for $15 \mathrm{~min}$ at $500 \times \mathrm{g}$ at $4^{\circ} \mathrm{C}$. Each pellet was resuspended in $100 \mu \mathrm{l}$ of Nuclei EZ storage buffer and stored at $-80^{\circ} \mathrm{C}$ until use for western blotting.

\section{Western blotting}

Standard SDS-PAGE western blotting was performed with $10 \%$ Tris- $\mathrm{HCl}$ acrylamide home-made gels or precast $10 \%$ gels (Bio-Rad). After electrophoresis, proteins were transferred onto PVDF membranes (Millipore). Briefly, membranes were then blocked in 5\% low fat milk in Tris buffer saline, $0.02 \%$ Tween 20 (TBST) pH 7.4 and were incubated overnight at $4^{\circ} \mathrm{C}$ with primary antibodies diluted in TBST. After 5 washings in TBST they were incubated with secondary peroxidase-conjugated antibodies for $1 \mathrm{~h}$ at room temperature. After 5 washings, the peroxidase signal was visualized by enhanced chemiluminescence, and if necessary, were enhanced by Super Signal West Femto Maximum Substrate (Fischer Scientific). The ECL films were scanned with a GS-800 Calibrated Densitometer. Image J software was used for the densitometric quantification of protein bands.

For western blotting of nuclear and cytoplasmic fractions, histone was used as nuclear marker and Disabled-1 (Dab1) or APP was used as cytoplasmic marker.

\section{Immunocytochemistry for SET subcellular localisation}

Cells were fixed with $4 \%$ paraformaldehyde for $30 \mathrm{~min}$ at room temperature, were rinsed 3 times in (PBS) and were saturated for $1 \mathrm{~h}$ at $37^{\circ} \mathrm{C}$ with $10 \%$ fetal calf serum in PBS, containing $0.2 \%$ Triton $\mathrm{X}-100$. The cells were incubated with antibodies (anti-SET or anti-HA, diluted to $1 / 200$ ) for $1 \mathrm{~h}$ at $37 \%$ in saturation buffer, were then rinsed 3 times in PBS, and were incubated with antirabbit cy3 or anti-mouse cy3 for $1 \mathrm{~h}$ at $37^{\circ} \mathrm{C}$. After 3 rinses in PBS the coverslips were mounted in a medium containing DAPI for epifluorescence microscopy. For confocal microscopy, nuclei were labeled by $0.1 \mu \mathrm{M}$ TOPRO-3 (Life Technologies, Illkirsch, France) for $15 \mathrm{~min}$ at room temperature, the coverslips were then rinsed 3 times in PBS and were mounted with Fluoromount-G (Clinisciences, Nanterre, France).

Immunofluorescence was analyzed by epifluorescence microscopy with an Axioplan 2 Zeiss with a x63 plan Apochromat oil immersion objective (numerical aperture 1.4). Digital images were acquired with a Sony DXC 
S500 colour digital camera. All pictures were shot at the same exposure time for each experiment.

The cells were also examined with a TCS SP5 confocal imaging system equipped with DPSS $561 \mathrm{~nm}$ and $\mathrm{HeNe}$ $633 \mathrm{~nm}$ lasers (Leica Microsystems, Mannheim, Germany). Eight bit digital images were collected in sequential mode with a x63 plan Apochromat oil immersion objective, a numerical aperture of 1.4, a zoom of 3 and the pinhole size "airy 1".

Microscopy was performed at the PICPEN platform (INSERM, UMR 894).

\section{Total phosphatase activity assay}

The mouse brain slice lysates were centrifuged at $16000 \times$ g for $15 \mathrm{~min}$ at $4^{\circ} \mathrm{C}$, then $\mathrm{NiCl}_{2}(2.5 \mathrm{mM}$ final $)$ and p-nitrophenyl phosphate (Sigma-Aldrich) $(1 \mathrm{mg} / \mathrm{ml}$ final) were added to supernatants, followed by incubation for $30 \mathrm{~min}$ at $37^{\circ} \mathrm{C}$. The reaction was stopped by the addition of $13 \% \mathrm{~K}_{2} \mathrm{HPO}_{4}$ and the absorbance of released p-nitrophenol was read at $405 \mathrm{~nm}$.

\section{PP2A immunoprecipitation and PP2A activity assay}

The mouse brain slice lysates were centrifuged at $16000 \times \mathrm{g}$ for $15 \mathrm{~min}$ at $4^{\circ} \mathrm{C}$, and the supernatants were incubated with the PP2A antibody for $2 \mathrm{~h}(5 \mu \mathrm{g}$ for $500 \mu \mathrm{g}$ of protein) at room temperature, followed by incubation with protein G Sepharose (Fisher Scientific) for $1 \mathrm{~h}$ at room temperature. The immunoprecipitates were washed carefully twice with $50 \mathrm{mM}$ Tris $\mathrm{pH} 7.5$, $50 \mathrm{mM} \mathrm{NaCl}$ followed by two washes in $50 \mathrm{mM} \mathrm{pH} 7.5$ Tris, $0.1 \mathrm{mM} \mathrm{CaCl}_{2} \mathrm{pH}$ 7.5. The immunoprecipitates were then suspended in $50 \mathrm{mM}$ Tris, $\mathrm{pH} 7.5$ assay buffer containing $0.1 \mathrm{mM} \mathrm{CaCl} 2,2.5 \mathrm{mM} \mathrm{NiCl}_{2}$ and $1 \mathrm{mg} / \mathrm{ml}$ p-nitrophenyl phosphate as a substrate, and were incubated at $37^{\circ} \mathrm{C}$ for $30 \mathrm{~min}$. The reaction was stopped by the addition of $13 \% \mathrm{~K}_{2} \mathrm{HPO}_{4}$ and the absorbance of released p-nitrophenol was read at $405 \mathrm{~nm}$.

\section{SET-PP2A co-immunoprecipitation}

Mouse brain slices incubated for 5 h $30 \mathrm{~min}$ with or without recombinant SET protein were prepared as described above. Washed slices were homogenized with a tissue grinder (Kontes glass $\mathrm{CO}$ ) in immunoprecipitation buffer (Hepes $10 \mathrm{mM}, \mathrm{NaCl} 150 \mathrm{mM}, \mathrm{CaCl}_{2} 2 \mathrm{mM}$, Triton $\mathrm{X}-1001 \% \mathrm{pH}$ 7.4) containing protease and phosphatase inhibitors and the resulting lysates were centrifuged at $16000 \times \mathrm{g}$ for $45 \mathrm{~min}$ at $4^{\circ} \mathrm{C}$. Proteins were quantified with the Micro BCA Protein Assay Kit (Fischer scientific). Lysates containing $1 \mathrm{mg}$ of protein in $400 \mu \mathrm{l}$ were precleared by incubation with $30 \mu \mathrm{l}$ of protein A Sepharose CL-4B (Fischer Scientific) for $1 \mathrm{~h}$ at $4^{\circ} \mathrm{C}$ on a rotating wheel. The clear supernatant was incubated overnight at $4^{\circ} \mathrm{C}$ on a rotating wheel with or without the polyclonal anti-SET. A total of $30 \mu \mathrm{l}$ of protein A Sepharose CL-4B was then added to each tube for $2 \mathrm{~h}$ at $4^{\circ} \mathrm{C}$ on a rotating wheel. The samples were centrifuged at $1000 \times \mathrm{g}$ for $10 \mathrm{~min}$ at $4^{\circ} \mathrm{C}$, and were then washed twice with immunoprecipitation buffer and a third time in the same buffer without Triton X-100. Samples were then suspended in NuPage LDS Sample Buffer (Bio-Rad) adjusted to 5\% $\beta$-mercaptoethanol and 5\% SDS, were boiled for $5 \mathrm{~min}$ and were centrifuged for $5 \mathrm{~min}$ at $16000 \times \mathrm{g}$ at room temperature. The supernatants were then analyzed by western blotting.

In some experiments, the Pierce Crosslinking Kit (Fischer Scientific) was used according to the manufacturer's procedure. Briefly, the pre-clearing step was performed with a control agarose resin for $1 \mathrm{~h}$ at $4^{\circ} \mathrm{C}$ on a rotating wheel. The polyclonal SET antibody was covalently coupled to protein A/G Plus agarose and was incubated with the pre-cleared lysate over night at $4^{\circ} \mathrm{C}$ on a rotating wheel. After four washes - the last without Triton $\mathrm{X}-100$ - the immunoprecipitated proteins were eluted with $30 \mu \mathrm{l}$ of the kit elution buffer in a tube containing $5 \mu \mathrm{l}$ of $1 \mathrm{M}$ Tris $\mathrm{pH} 9.5$ to neutralize the low $\mathrm{pH}$ of the elution buffer.

\section{Real time PCR for mRNA quantification}

Neurons at 5 DIV were incubated for $1 \mathrm{~h} 30 \mathrm{~min}, 2 \mathrm{~h}$ $30 \mathrm{~min}, 3 \mathrm{~h} 30 \mathrm{~min}$ or $5 \mathrm{~h} 30 \mathrm{~min}$ with $2 \mu \mathrm{M}$ of Jcasp peptide or $2 \mu \mathrm{M}$ of Penetratin. The medium was removed and the cells were washed once in PBS and then collected by scraping. Total RNA was extracted with the RNeasy mini kit and was treated with DNaseI (Qiagen, Courtaboeuf, France). cDNA was prepared from total RNA samples with the High Capacity cDNA Reverse Transcription kit (Life Technologies, Saint Aubin, France). Briefly, $20 \mu \mathrm{l}$ of reaction mixture containing 100 ng of total RNA, $1 \mathrm{X}$ reverse transcription buffer, $1 \mathrm{mM}$ of each dNTP, $1 \mathrm{X}$ reverse transcription random primer and $50 \mathrm{U}$ of MultiScribe reverse transcriptase were incubated at $25^{\circ} \mathrm{C}$ for $10 \mathrm{~min}$ followed by incubation at $37^{\circ} \mathrm{C}$ for $2 \mathrm{~h}$. The reaction was stopped by heating at $85^{\circ} \mathrm{C}$ for $5 \mathrm{sec}$. Real time PCR was performed with an Abi Prism 7000 and the Absolute SYBR Green ROX Mix (Fischer Scientific). A total of $25 \mathrm{ng}$ of cDNA was mixed with $0.07 \mathrm{mM}$ of each primer, 1X SYBR Green Mix and PCR-grade water to a final volume of $25 \mu$ l. The cycling conditions for all primers (Set forward: TTACTGACCATTCTGACGCA, Set reverse: CTGCCTCTCCTTCTTCATCA, Gapdh forward: CCAACACTGAGCATCTCCCT and Gapdh reverse: GGGTGCAGCGAACTTTATTG) were $50^{\circ} \mathrm{C}$ for $2 \mathrm{~min}$, then $95^{\circ} \mathrm{C}$ for $15 \mathrm{~min}$ followed by 40 cycles consisting of two steps, $15 \mathrm{sec}$ at $95^{\circ} \mathrm{C}$ and $1 \mathrm{~min}$ at $60^{\circ} \mathrm{C}$. The PCR program was completed by a melting temperature analysis consisting of $15 \mathrm{sec}$ at $95^{\circ} \mathrm{C}, 20 \mathrm{sec}$ at $60^{\circ} \mathrm{C}$ and then steps through which temperature ranged from 60 to $95^{\circ} \mathrm{C}$. Amplification plots were produced to calculate 
the threshold cycle $(\mathrm{Ct})$ and standard curves of $\mathrm{Ct}$ versus log cDNA dilution were generated for both target (SET) and reference (GAPDH) genes. All reactions were done in triplicate and the average $\mathrm{Ct}$ was used. Relative quantification was calculated with the $2^{-\Delta \Delta C t}$ method. Gene expression in Jcasp peptide treated neurons was calculated relative to that of Penetratin treated cells.

\section{Statistical analysis}

Significance was assessed with the analysis of variance (ANOVA) and post-hoc Scheffe's test (StatView). Results were expressed as mean value \pm SEM.

\section{Additional file}

Additional file 1: Figure S1 Differences in hyperphosphorylated tau isoforms in cells treated with OA, Jcasp peptide or recombinant SET protein. Mouse brain slices were treated with recombinant SET protein or Jcasp peptide for $5 \mathrm{~h} 30 \mathrm{~min}$, and proteins were then extracted and prepared (40 $\mathrm{\mu g}$ per lane) for western blotting. Various residues that may be hyperphosphorylated on tau were analyzed. Okadaic acid (OA) was used as positive control. Brain slices not treated with recombinant SET were used as a control (Ctrl). Jcasp and SET induce hyperphosphorylation of the same tau isoforms. In some cases these hyperphosphorylated tau isoforms differ from those induced by okadaic acid (OA). Representative examples of two independent experiments are shown (A, B). Note that for the same mouse brain, the tau isoforms phosphorylated at the Ser-422 epitope were identical for OA and recombinant SET, contrary to what we observed for Ser-202 (B).

\section{Competing interests}

The authors declare that they have no competing interests.

\section{Authors' contributions}

SC, CC, BA conceived and designed experiments. SC and CC performed biochemical experiments. $L H$ and $L G$ performed immunocytochemical experiments. SC, CC, CR and BA analyzed data. SC, CC, BA wrote the paper. All authors read and approved the final manuscript.

\section{Acknowledgements}

This work was supported by Agence Nationale pour la Recherche (06-Neuro-046), Fondation Jérôme Lejeune, France Alzheimer, Fédération pour la Recherche sur le Cerveau, Institut National pour la Santé et la Recherche Médicale.

\section{Author details}

'INSERM UMR 894, Université Paris Descartes, Sorbonne Paris Cité, Faculté de Médecine, Paris, France. ${ }^{2}$ Inserm, U1 144, Paris F-75006, France. ${ }^{3}$ Université Paris Descartes, UMR-S 1144, Paris F-75006, France. ${ }^{4}$ Université Paris Diderot, UMR-S 1144, Paris F-75013, France.

Received: 6 May 2014 Accepted: 25 June 2014

Published: 30 June 2014

\section{References}

1. Sergeant N, Delacourte A, Buee L: Tau protein as a differential biomarker of tauopathies. Biochim Biophys Acta 2005, 1739(2-3):179-197.

2. Brion JP: Immunological demonstration of tau protein in neurofibrillary tangles of Alzheimer's disease. J Alzheimers Dis 2006, 9(3 Suppl):177-185.

3. Wang JZ, Xia YY, Grundke-lqbal I, lqbal K: Abnormal hyperphosphorylation of tau: sites, regulation, and molecular mechanism of neurofibrillary degeneration. J Alzheimers Dis 2013, 33(Suppl 1):S123-S139.

4. Janssens V, Goris J: Protein phosphatase $2 A$ : a highly regulated family of serine/threonine phosphatases implicated in cell growth and signalling. Biochem J 2001, 353(Pt 3):417-439.
5. Xu Y, Xing $Y$, Chen $Y$, Chao $Y$, Lin Z, Fan E, Yu JW, Strack S, Jeffrey PD, Shi Y: Structure of the protein phosphatase 2A holoenzyme. Cell 2006, 127(6):1239-1251.

6. Cho US, Xu W: Crystal structure of a protein phosphatase 2A heterotrimeric holoenzyme. Nature 2007, 445(7123):53-57.

7. Lee J, Stock J: Protein phosphatase $2 \mathrm{~A}$ catalytic subunit is methyl-esterified at its carboxyl terminus by a novel methyltransferase. J Biol Chem 1993, 268(26):19192-19195.

8. Xie $\mathrm{H}$, Clarke $\mathrm{S}$ : Protein phosphatase $2 \mathrm{~A}$ is reversibly modified by methyl esterification at its $\mathrm{C}$-terminal leucine residue in bovine brain. J Biol Chem 1994, 269(3):1981-1984.

9. Favre B, Zolnierowicz S, Turowski P, Hemmings BA: The catalytic subunit of protein phosphatase 2A is carboxyl-methylated in vivo. J Biol Chem 1994, 269(23):16311-16317.

10. Wu J, Tolstykh T, Lee J, Boyd K, Stock JB, Broach JR: Carboxyl methylation of the phosphoprotein phosphatase $2 \mathrm{~A}$ catalytic subunit promotes its functional association with regulatory subunits in vivo. Embo J 2000, 19(21):5672-5681.

11. Liu R, Zhou XW, Tanila H, Bjorkdahl C, Wang JZ, Guan ZZ, Cao Y, Gustafsson JA, Winblad B, Pei JJ: Phosphorylated PP2A (tyrosine 307) is associated with Alzheimer neurofibrillary pathology. J Cell Mol Med 2008, 12(1):241-257.

12. Gong CX, Singh TJ, Grundke-lqbal I, labal K: Phosphoprotein phosphatase activities in Alzheimer disease brain. J Neurochem 1993, 61(3):921-927.

13. Gong CX, Shaikh S, Wang JZ, Zaidi T, Grundke-lqbal I, lqbal K: Phosphatase activity toward abnormally phosphorylated tau: decrease in Alzheimer disease brain. J Neurochem 1995, 65(2):732-738.

14. Pei JJ, Sersen E, Iqbal K, Grundke-lqbal I: Expression of protein phosphatases (PP-1, PP-2A, PP-2B and PTP-1B) and protein kinases (MAP kinase and P34cdc2) in the hippocampus of patients with Alzheimer disease and normal aged individuals. Brain Res 1994, 655(1-2):70-76.

15. Sontag E, Hladik C, Montgomery L, Luangpirom A, Mudrak I, Ogris E, White $\mathrm{CL}$ 3rd: Downregulation of protein phosphatase 2A carboxyl methylation and methyltransferase may contribute to Alzheimer disease pathogenesis. J Neuropathol Exp Neurol 2004, 63(10):1080-1091.

16. Yoon SY, Choi HI, Choi JE, Sul CA, Choi JM, Kim DH: Methotrexate decreases PP2A methylation and increases tau phosphorylation in neuron. Biochem Biophys Res Commun 2007, 363(3):811-816.

17. Zhou XW, Gustafsson JA, Tanila H, Bjorkdahl C, Liu R, Winblad B, Pei JJ: Tau hyperphosphorylation correlates with reduced methylation of protein phosphatase 2A. Neurobiol Dis 2008, 31(3):386-394.

18. Li M, Guo H, Damuni Z: Purification and characterization of two potent heat-stable protein inhibitors of protein phosphatase $2 \mathrm{~A}$ from bovine kidney. Biochemistry 1995, 34(6):1988-1996.

19. Seo SB, McNamara P, Heo S, Turner A, Lane WS, Chakravarti D: Regulation of histone acetylation and transcription by INHAT, a human cellular complex containing the set oncoprotein. Cell 2001, 104(1):119-130.

20. Fan Z, Beresford PJ, Oh DY, Zhang D, Lieberman J: Tumor suppressor NM23-H1 is a granzyme A-activated DNase during CTL-mediated apoptosis, and the nucleosome assembly protein SET is its inhibitor. Cell 2003, 112(5):659-672.

21. Compagnone NA, Zhang P, Vigne $J$, Mellon SH: Novel role for the nuclear phosphoprotein SET in transcriptional activation of P450c17 and initiation of neurosteroidogenesis. Mol Endocrinol 2000, 14(6):875-888.

22. Qu D, Li Q, Lim HY, Cheung NS, Li R, Wang JH, Qi RZ: The protein SET binds the neuronal Cdk5 activator p35nck5a and modulates Cdk5/ p35nck5a activity. J Biol Chem 2002, 277(9):7324-7332.

23. Li M, Makkinje A, Damuni Z: The myeloid leukemia-associated protein SET is a potent inhibitor of protein phosphatase 2A.J Biol Chem 1996, 271(19):11059-11062.

24. Blalock EM, Geddes JW, Chen KC, Porter NM, Markesbery WR, Landfield PW: Incipient Alzheimer's disease: microarray correlation analyses reveal major transcriptional and tumor suppressor responses. Proc Natl Acad SCi U S A 2004, 101(7):2173-2178.

25. Tanimukai H, Grundke-lqbal I, lqbal K: Up-regulation of inhibitors of protein phosphatase-2A in Alzheimer's disease. Am J Pathol 2005, 166(6):1761-1771.

26. Facchinetti P, Dorard E, Contremoulins V, Gaillard MC, Deglon N, Sazdovitch V, Guihenneuc-Jouyaux C, Brouillet E, Duyckaerts C, Allinquant B: SET translocation is associated with increase in caspase cleaved amyloid precursor protein in CA1 of Alzheimer and Down syndrome patients. Neurobiol Aging 2014, 35(5):958-968. 
27. Madeira A, Pommet JM, Prochiantz A, Allinquant B: SET protein (TAF1beta, I2PP2A) is involved in neuronal apoptosis induced by an amyloid precursor protein cytoplasmic subdomain. Faseb J 2005, 19(13):1905-1907.

28. Briand S, Facchinetti P, Clamagirand C, Madeira A, Pommet JM, Pimplikar SW, Allinquant B: PAT1 induces cell death signal and SET mislocalization into the cytoplasm by increasing APP/APLP2 at the cell surface. Neurobiol Aging 2011, 32(6):1099-1113.

29. Qu D, Zhang Y, Ma J, Guo K, Li R, Yin Y, Cao X, Park DS: The nuclear localization of SET mediated by impalpha3/impbeta attenuates its cytosolic toxicity in neurons. J Neurochem 2007, 103(1):408-422.

30. Tsujio I, Zaidi T, Xu J, Kotula L, Grundke-lqbal I, Iqbal K: Inhibitors of protein phosphatase-2A from human brain structures, immunocytological localization and activities towards dephosphorylation of the Alzheimer type hyperphosphorylated tau. FEBS Lett 2005, 579(2):363-372.

31. Chohan MO, Khatoon S, Iqbal IG, Iqbal K: Involvement of I2PP2A in the abnormal hyperphosphorylation of tau and its reversal by Memantine. FEBS Lett 2006, 580(16):3973-3979.

32. Liu Z, Jang SW, Liu X, Cheng D, Peng J, Yepes M, Li XJ, Matthews S, Watts C, Asano M, Hara-Nishimura I, Luo HR, Ye K: Neuroprotective actions of PIKE-L by inhibition of SET proteolytic degradation by asparagine endopeptidase. Mol Cell 2008, 29(6):665-678.

33. Basurto-Islas G, Grundke-lqbal I, Tung YC, Liu F, Iqbal K: Activation of asparaginyl endopeptidase leads to Tau hyperphosphorylation in Alzheimer disease. J Biol Chem 2013, 288(24):17495-17507.

34. Arnaud L, Chen S, Liu F, Li B, Khatoon S, Grundke-lqbal I, labal K: Mechanism of inhibition of PP2A activity and abnormal hyperphosphorylation of tau by I2(PP2A)/SET. FEBS Lett 2011, 585(17):2653-2659.

35. Wang X, Blanchard J, Kohlbrenner E, Clement N, Linden RM, Radu A, Grundke-lqbal I, lqbal K: The carboxy-terminal fragment of inhibitor-2 of protein phosphatase-2A induces Alzheimer disease pathology and cognitive impairment. Faseb J 2010, 24(11):4420-4432.

36. Bolognin S, Blanchard J, Wang X, Basurto-Islas G, Tung YC, Kohlbrenner E, Grundke-lqbal I, lqbal K: An experimental rat model of sporadic Alzheimer's disease and rescue of cognitive impairment with a neurotrophic peptide. Acta Neuropathol 2012, 123(1):133-151.

37. Ayala-Grosso C, Ng G, Roy S, Robertson GS: Caspase-cleaved amyloid precursor protein in Alzheimer's disease. Brain Pathol 2002, 12(4):430-441.

38. Zhao M, Su J, Head E, Cotman CW: Accumulation of caspase cleaved amyloid precursor protein represents an early neurodegenerative event in aging and in Alzheimer's disease. Neurobiol Dis 2003, 14(3):391-403.

39. Banwait S, Galvan V, Zhang J, Gorostiza OF, Ataie M, Huang W, Crippen D, Koo EH, Bredesen DE: C-terminal cleavage of the amyloid-beta protein precursor at Asp664: a switch associated with Alzheimer's disease. J Alzheimers Dis 2008, 13(1):1-16.

40. Bertrand E, Brouillet E, Caille I, Bouillot C, Cole GM, Prochiantz A, Allinquant $B$ : A short cytoplasmic domain of the amyloid precursor protein induces apoptosis in vitro and in vivo. Mol Cell Neurosci 2001, 18(5):503-511.

41. Gong CX, Lidsky T, Wegiel J, Zuck L, Grundke-lqbal I, labal K: Phosphorylation of microtubule-associated protein tau is regulated by protein phosphatase $2 \mathrm{~A}$ in mammalian brain. Implications for neurofibrillary degeneration in Alzheimer's disease. J Biol Chem 2000, 275(8):5535-5544.

42. Liu F, Grundke-lqbal I, lqbal K, Gong CX: Contributions of protein phosphatases PP1, PP2A, PP2B and PP5 to the regulation of tau phosphorylation. Eur J Neurosci 2005, 22(8):1942-1950.

43. Watanabe A, Hasegawa M, Suzuki M, Takio K, Morishima-Kawashima M, Titani K, Arai T, Kosik KS, Ihara Y: In vivo phosphorylation sites in fetal and adult rat tau. J Biol Chem 1993, 268(34):25712-25717.

44. Matsuo ES, Shin RW, Billingsley ML, Vande Voorde A, O'Connor M, Trojanowski JQ, Lee VM: Biopsy-derived adult human brain tau is phosphorylated at many of the same sites as Alzheimer's disease paired helical filament tau. Neuron 1994, 13(4):989-1002.

45. Goedert M, Jakes R, Crowther RA, Six J, Lubke U, Vandermeeren M, Cras P, Trojanowski JQ, Lee VM: The abnormal phosphorylation of tau protein at Ser-202 in Alzheimer disease recapitulates phosphorylation during development. Proc Natl Acad Sci U S A 1993, 90(11):5066-5070.

46. Hasegawa M, Jakes $R$, Crowther RA, Lee VM, Ihara Y, Goedert M: Characterization of $\mathrm{mAb}$ AP422, a novel phosphorylation-dependent monoclonal antibody against tau protein. FEBS Lett 1996, 384(1):25-30

47. Yu G, Yan T, Feng Y, Liu X, Xia Y, Luo H, Wang JZ, Wang X: Ser9 phosphorylation causes cytoplasmic detention of I2PP2A/SET in Alzheimer disease. Neurobiol Aging 2013, 34(7):1748-1758.

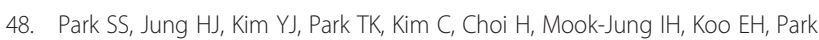
SA: Asp664 cleavage of amyloid precursor protein induces tau phosphorylation by decreasing protein phosphatase $2 \mathrm{~A}$ activity. J Neurochem 2012, 123(5):856-865.

49. Lee J, Chen Y, Tolstykh T, Stock J: A specific protein carboxyl methylesterase that demethylates phosphoprotein phosphatase $2 \mathrm{~A}$ in bovine brain. Proc Natl Acad Sci U S A 1996, 93(12):6043-6047.

50. Xing Y, Li Z, Chen Y, Stock JB, Jeffrey PD, Shi Y: Structural mechanism of demethylation and inactivation of protein phosphatase 2A. Cell 2008, 133(1):154-163.

51. Sontag JM, Nunbhakdi-Craig $\vee$, Sontag E: Leucine carboxyl methyltransferase 1 (LCMT1)-dependent methylation regulates the association of protein phosphatase $2 \mathrm{~A}$ and Tau protein with plasma membrane microdomains in neuroblastoma cells. J Biol Chem 2013, 288(38):27396-27405.

52. Sontag E, Nunbhakdi-Craig V, Lee G, Bloom GS, Mumby MC: Regulation of the phosphorylation state and microtubule-binding activity of Tau by protein phosphatase 2A. Neuron 1996, 17(6):1201-1207.

53. Kirchhefer $U$, Heinick A, Konig S, Kristensen T, Muller FU, Seidl MD, Boknik P: Protein phosphatase $2 \mathrm{~A}$ is regulated by protein kinase Calpha (PKCalpha)-dependent phosphorylation of its targeting subunit B56alpha at Ser41. J Biol Chem 2014, 289(1):163-176.

54. Qian W, Shi J, Yin X, lqbal K, Grundke-lqbal I, Gong CX, Liu F: PP2A regulates Tau phosphorylation directly and also indirectly via activating GSK-3beta. J Alzheimers Dis 2010, 23(4):617-627.

55. Torrent L, Ferrer I: PP2A and Alzheimer disease. Curr Alzheimer Res 2012, 9(2):248-256.

56. Lafont F, Rouget M, Rousselet A, Valenza C, Prochiantz A: Specific responses of axons and dendrites to cytoskeleton perturbations: an in vitro study. J Cell Sci 1993, 104(Pt 2):433-443.

57. Rose C, Camus A, Schwartz JC: Protection by serine peptidase inhibitors of endogenous cholecystokinin released from brain slices. Neuroscience 1989, 29(3):583-594.

doi:10.1186/1471-2202-15-82

Cite this article as: Chasseigneaux et al.: Cytoplasmic SET induces tau hyperphosphorylation through a decrease of methylated phosphatase $2 \mathrm{~A}$. BMC Neuroscience 2014 15:82.

\section{Submit your next manuscript to BioMed Central and take full advantage of:}

- Convenient online submission

- Thorough peer review

- No space constraints or color figure charges

- Immediate publication on acceptance

- Inclusion in PubMed, CAS, Scopus and Google Scholar

- Research which is freely available for redistribution 